\title{
Immune Evasion Mechanisms of Entamoeba histolytica: Progression to Disease
}

\author{
Sharmin Begum, Jeanie Quach and Kris Chadee * \\ Department of Microbiology, Immunology and Infectious Diseases, Cumming School of Medicine, Snyder Institute for \\ Chronic Diseases, University of Calgary, Calgary, AB, Canada
}

\section{OPEN ACCESS}

Edited by:

Alexandre Morrot,

Federal University of Rio de Janeiro,

Brazil

Reviewed by:

Alberto A. Iglesias,

Instituto de Agrobiotecnología del Litoral (UNL-CONICET), Argentina

Thomas Dandekar,

University of Würzburg, Germany

Fabricio Montalvão Ferreira,

Universidade Federal do Rio de

Janeiro, Brazil

*Correspondence:

Kris Chadee

kchadee@ucalgary.ca

Specialty section:

This article was submitted to

Microbial Immunology,

a section of the journal

Frontiers in Microbiology

Received: 16 September 2015 Accepted: 23 November 2015

Published: 15 December 2015

Citation:

Begum S, Quach J and Chadee K (2015) Immune Evasion Mechanisms of Entamoeba histolytica: Progression to Disease. Front. Microbiol. 6:1394. doi: 10.3389/fmicb.2015.01394
Entamoeba histolytica (Eh) is a protozoan parasite that infects $10 \%$ of the world's population and results in 100,000 deaths/year from amebic dysentery and/or liver abscess. In most cases, this extracellular parasite colonizes the colon by high affinity binding to MUC2 mucin without disease symptoms, whereas in some cases, Eh triggers an aggressive inflammatory response upon invasion of the colonic mucosa. The specific host-parasite factors critical for disease pathogenesis are still not well characterized. From the parasite, the signature events that lead to disease progression are cysteine protease cleavage of the C-terminus of MUC2 that dissolves the mucus layer followed by Eh binding and cytotoxicity of the mucosal epithelium. The host mounts an ineffective excessive host pro-inflammatory response following contact with host cells that causes tissue damage and participates in disease pathogenesis as Eh escapes host immune clearance by mechanisms that are not completely understood. Ameba can modulate or destroy effector immune cells by inducing neutrophil apoptosis and suppressing respiratory burst or nitric oxide (NO) production from macrophages. Eh adherence to the host cells also induce multiple cytotoxic effects that can promote cell death through phagocytosis, apoptosis or by trogocytosis (ingestion of living cells) that might play critical roles in immune evasion. This review focuses on the immune evasion mechanisms that Eh uses to survive and induce disease manifestation in the host.

Keywords: Entamoeba histolytica, immune evasion, phagocytosis, apoptosis, trogocytosis

\section{INTRODUCTION}

Entamoeba histolytica (Eh), the causative agent of amebiasis, is an intestinal protozoan parasite that colonizes the intestinal lumen asymptomatically (known as noninvasive disease) in approximately $90 \%$ of cases. However, in $10 \%$ of individuals, this asymptomatic relationship breaks down and the parasite breaches the innate mucosal barrier and invades the underlying lamina propria resulting in 100,000 death per year globally (Stanley, 2003). Parasite cysts are acquired through the ingestion of contaminated food and water mostly in areas of poor sanitation (Ralston and Petri, 2011a). Birth cohort studies done in an urban slum in Dhaka, Bangladesh found that approximately $50 \%$ of infants are infected in the first year of life, with repeated infections that are connected with malnourishment and stunting (Mondal et al., 2006; Korpe et al., 2013). The exact reasons why Eh occasionally invade the mucosal epithelium and what host-parasite factors are involved in parasite invasion are not clear. The outcome of invasive Eh infection is variable; it can result in amebic diarrhea, amebic colitis, and/or dissemination of the parasites through the portal circulation to cause liver abscess (Ralston and Petri, 2011b). Eh invasion induces a robust pro-inflammatory 
response and host tissue destruction that exacerbates disease (Moonah et al., 2013; Mortimer et al., 2015). Currently, there is no effective vaccine for this disease; however nitroimidazoles (such as metronidazole) are effective to treat this tissue dwelling parasites. Metronidazole treatment can cause toxic side effects and enhance the probability of developing drug resistant (Petri, 2003; Ralston and Petri, 2011b). Our host immune system sets up a series of defensive responses against the parasite. However, continued morbidity and mortality point out that this parasite is capable of escaping host defense responses to maintain its own survival (Moonah et al., 2013). Thus, an understanding of the human immune response to the parasite and the strategies used by the parasite to evade host defense will deeply improve the development of effective immunotherapies. In this review, we will focus on the host immune responses against $E h$ and the complex strategies the parasite uses to evade host immunity.

\section{HOST IMMUNITY AGAINST E. histolytica}

\section{Innate and Adaptive Immune Response}

For any ingested parasite, immunity begins from the stomach acid as it has the ability to kill acid-sensitive microorganisms. However, the mucus barrier of the intestine serves as the first protective layer that prevents $E h$ from making contact with the underlying intestinal epithelial cells (IECs; Moonah et al., 2013). There are three major virulent factors of Eh known to mediate pathogenicity: (1) galactose/ $\mathrm{N}$-acetylgalactosamine-inhibitable lectin (Gal-lectin) is responsible for binding colonic mucin in colonization and host cell adhesion in disease pathogenesis, (2) pore forming peptide amoebapore used for host cell killing and, (3) cysteine proteases that lyse host extracellular matrix (Campos-Rodríguezp and Jarillo-Luna, 2005) and stimulate proinflammatory responses. The mucus barrier in the colon is composed of MUC2 mucin, which is a glycoprotein secreted from goblet cells. Mucin binds with high affinity to Eh Gal-lectin allowing the parasite to colonize the gut and at the same time it acts as a physical barrier to inhibit parasite invasion of the underlying epithelium (Chadee et al., 1987; Moonah et al., 2013). When Eh overcomes innate host defenses and contact IECs they produce a variety of pro-inflammatory mediators/chemokines including interleukin-1 (IL-1 $\beta$ ), interleukin-8 (IL-8), and TNF$\alpha$. Several of these mediators trigger the recruitment of immune cells including neutrophils and macrophages to the site of parasite invasion (Yu and Chadee, 1997). The main amebicidal activity of neutrophils is the release of reactive oxygen species (ROS; Guerrant et al., 1981; Denis and Chadee, 1989). In macrophages Eh Gal-lectin up-regulates the mRNA expression of different cytokines. Gal-lectin induces pattern recognition receptor (PRRs) such as TLR-2 and TLR-4 mRNA expression in macrophages which is controlled by nuclear factor NF- $\mathrm{B}$ and MAPK pathway. Recognition of parasite molecules by surface PRRs are crucial for the up-regulation of pro-inflammatory cytokine expression via NF-кB (Kammanadiminti et al., 2004). Macrophages activated with cytokines such as IFN- $\gamma$ or TNF$\alpha$ kills Eh trophozoites in vitro by producing nitric oxide (NO) from L-arginine mediated by inducible nitric oxide synthase
(iNOS) (Lin et al., 1994). NO is critical for macrophage-mediated killing as iNOS deficient mice are more vulnerable to amebic liver abscess (ALA) and hepatocytic apoptosis (Seydel et al., 2000). Interferon gamma (IFN- $\gamma$ ) is the major cytokine that activates neutrophils and macrophages to exert amebicidal activity. Higher levels of IFN- $\gamma$ are related to a lower incidence of $E h$ infection (Denis and Chadee, 1989; Ghadirian and Denis, 1992; Haque et al., 2007).

Humoral immune responses against $E h$ are well characterized and it was been found that $81-100 \%$ of invasive amebiasis patients develop circulatory antibodies within 7 days of infection (Kaur et al., 2004). A prospective cohort study of pre-school children in Dhaka, Bangladesh, showed that mucosal IgA antibodies against the carbohydrate recognition domain (CRD) of the Gal-lectin heavy chain provided protection against Eh infection and disease (Haque et al., 2001, 2006). In contrast, serum anti-lectin IgG was not associated with protection but mainly with the frequency of new infection (Haque et al., 2001). Higher levels of anti-lectin IgG was found in ALA and intestinal amebiasis as compared to asymptomatic patients (Kaur et al., 2004). These findings indicate that systematic antilectin antibodies are not involved in direct protection against amebiasis.

\section{Inflammasome Activation by E. histolytica}

Eh imposes damage through the adherence to host cells, which plays a critical role in killing or ingesting host target (Mortimer and Chadee, 2010). Thus, amebae adherence to host cell is one of the major characteristics of Eh pathogenicity. At present, the pattern recognition receptors (PRRs) that bind Eh Gal-lectin are not known. We recently identified that the inflammasome pathway is only activated on contact with live $E h$ and distinguishes between different physical forms of Eh (Mortimer et al., 2014). Inflammasome is a cytosolic multiprotein complex, which acts as a sensor for pathogens and cellular damage. This multimeric complex consists of an inflammasome sensor molecule (NOD-like receptor), the adaptor protein ASC and caspase-1. Activation of inflammasome leads to rapid and robust secretion of IL-1 $\beta$, IL-18, IL-1 $\alpha$, FGF-2, IP-10 (Mortimer et al., 2014). Interestingly, when Eh activates the inflammasome, it does not trigger caspase-1 dependent cell death (known as pyroptosis) (Mortimer et al., 2014). It is unclear if inflammasome-activated macrophages are amebicidal and whether it plays other protective roles in amebic infection. On the other hand, if inflammasome activation triggers cell death in macrophages (pyroptotic cell death), Eh can use it as an advantage to limit immune elimination that can become detrimental to host defense.

\section{IMMUNE EVASION MECHANISMS OF E. histolytica}

Eh has a two-phase life cycle: it can survive as an infective cyst in the environment or it can be found as trophozoites, the feeding and tissue dwelling stage in the human colon. After excystation in the colon, Eh trophozoites usually establishes harmless colonization where the parasites reside in the gut lumen and feed on enteric bacteria by phagocytosis (Voigt et al., 1999; 
Wilson et al., 2012). However, for unknown reasons trophozoites can become invasive, where parasite virulence factors allow it to degrade colonic mucin and other innate epithelial barrier functions (Wilson et al., 2012). Host immune responses, both innate and adaptive, are robust against invasive $E h$ but still this parasite is able to survive by developing immune evasion strategies. In particular, Eh cysteine proteases can cleave MUC2 mucin abrogating its protective functions allowing the parasite to breach the mucus layer and attach to the underlying epithelial cells (Lidell et al., 2006). Intestinal antimicrobial peptides are also an important component of host innate immune defense. Even though human LL-37 and murine CRAMP (cathelinrelated antimicrobial peptide) cathelicidins are induced by $E h$ trophozoites both at the mRNA and protein level in IECs, Eh cysteine proteases can cleave these antimicrobial peptides (Cobo et al., 2012). Thus, Eh is resistant to both intact and cleaved antimicrobial cathelicidins in the intestine (Cobo et al., 2012).

After amebic invasion, neutrophils are the earliest infiltrating cells but virulent $E h$ are effective in killing, lysing, and phagocytosing neutrophils. In vitro, one trophozoite was shown to kill approximately 3000 neutrophils (Guerrant et al., 1981; Guo et al., 2007). There are several conflicting mechanisms by which ameba interfere with neutrophil functions. Eh can disrupt NADPH oxidase activities and inhibit the respiratory burst of neutrophils to avoid oxidative stress. Eh iron-containing superoxide dismutase and NADPH:flavin oxidoreductase (Elnekave et al., 2003) are able to detoxify ROS by forming $\mathrm{H}_{2} \mathrm{O}_{2}$ (Bruchhaus et al., 1998; Sim et al., 2005). Eh trophozoites can protect themselves from neutrophil reactive oxygen properties with a $29-\mathrm{kDa}$ surface protein, peroxiredoxin that has potent antioxidant activity (Davis et al., 2006). Studies have shown (Sim et al., 2005) that Eh can induce host cells (neutrophil) apoptosis through the activation of ERK1/2 by the generation of NADPH oxidase-derived ROS.

Macrophages, another effector cell present during amebic infection also show suppressed cell mediated immunity due to Eh-induced strategic immune modulation. Eh trophozoites inhibit respiratory burst (ROS: $\mathrm{H}_{2} \mathrm{O}_{2}, \mathrm{O}^{2-}, \mathrm{OH}^{-}$) and $\mathrm{NO}$ production by macrophages (Lin et al., 1993; Wang et al., 1994). NOS substrate L-arginine is competitively converted to L-ornithine by ameba arginase that limit NO production by macrophages (Elnekave et al., 2003). When Eh and macrophages are exposed to each other, ameba produces the immunoregulatory molecule prostaglandin E2 $\left(\mathrm{PGE}_{2}\right)$, synthesized by a cyclooxygenase (COX)-like enzyme by the parasite (Dey et al., 2003). Coupling through EP2/4 receptors, $\mathrm{PGE}_{2}$ increases cyclic adenosine monophosphate (cAMP) levels in macrophages that inhibits Th1 cytokine release, NADPH-mediated oxidative burst, and NO synthesis through the protein kinase C (PKC) pathway (Wang and Chadee, 1995). Another immunosuppressive pentapeptide, monocyte locomotion inhibitory factor (MLIF) produced by Eh showed anti-inflammatory activities by inhibiting NO production (Rico et al., 2003).

The complement system of the host is able to prevent trophozoite dissemination into the extra intestinal space. Activated complement forms the membrane attack complex
(MAC) that can potentially lyse the parasite. Eh resists complement activation by the Gal-lectin which have sequence resemblance and antigenic cross reactivity with the MACinhibitory protein CD59 and thus inhibit MAC-mediated lysis (Braga et al., 1992). Cysteine proteases can also cleave complement components (Reed et al., 1995). The potent proinflammatory activities of the complement component $\mathrm{C} 3 \mathrm{a}$ and $\mathrm{C} 5 \mathrm{a}$ are degraded by $E$ h secreted extracellular cysteine proteases (Zambrano-Villa et al., 2002). Secretory IgA and serum IgG mediate adaptive immunity against $E h$ and ameba can degrade these immunoglobulins in vitro. Eh extracellular cysteine proteases play a key role in the disruption of host adaptive defenses. For successful invasion, Eh secreted and membranebound cysteine proteases cleave extracellular matrix proteins, fibronectin, and laminin and avoid host defenses by cleaving gut lumen sIgA and circulatory IgG (Que and Reed, 1997; Zambrano-Villa et al., 2002).

\section{E. histolytica-induced Cell Death: Immune Evasion Strategy}

Eh uses different strategies to evade host immune defense but one striking mechanism is the induction of host cell death. The term "histolytica" refers to Eh ability to destroy host tissues by potent cytotoxicity/cell killing activity toward different host cells including neutrophils, macrophages, T-lymphocytes; though the exact mechanism of host cell killing is not clear. Eh has several cytotoxic effector molecules (Table 1) but how ameba deliver this deadly action is not clear. Eh can induce host cell apoptosis, phagocytosis and amebic trogocytosis; the latter involving a recently described mechanism of ameba-induced host cell killing (Ralston et al., 2014).

\section{Apoptotic Cell Death}

Host cell killing is usually a stepwise process mediated by parasite adherence to the target cell, elevation of intracellular calcium level, dephosphorylation of host proteins which all contribute to cell death via activation of caspase-3 (Ralston and Petri, 2011b). Caspase- 3 activation is the signature event of apoptosis. The first step of adherence is mediated by the parasite surface Gal-lectin to host cell carbohydrate determinants containing Gal and/or GalNAc residues (Figure 1A). Gal-lectin mediated adherence to target cell is a prerequisite for parasite cytotoxicity as the addition of excess Gal or GalNAc monomers inhibit Eh adherence and target cell killing (Ravdin and Guerrant, 1981; Saffer and Petri, 1991). Adherence to the target cell induces calcium flux which also contribute to the cell killing proved by the inhibition of calcium channel or by using calcium chelators (Ravdin et al., 1982; Ralston and Petri, 2011b). Amebic cytotoxicity both in vitro and in vivo occurs via the caspase- 3 dependent apoptotic cell death pathway in Jurkat cells after contact with Eh (Figures 1A,C) (Seydel and Stanley, 1998; Ralston and Petri, 2011b). Caspase-3 knockout mice are resistant to amebiasis and a pharmacological inhibitor of caspase-3, Ac-DEVD-CHO (Nacetyl-Asp-Glu-Val-Asp-aldehyde) reduces parasite cytotoxicity to host cells (Huston et al., 2000; Becker et al., 2010). Studies illustrate that Eh-induced apoptosis is independent of caspase8 or caspase- 9 (Huston et al., 2000). Another study showed that 
TABLE 1 | Potential cytotoxic effector molecules identified in Entamoeba histolytica.

\begin{tabular}{|c|c|c|}
\hline Eh effectors molecules & Identified effect on host cell & References \\
\hline \multirow[t]{2}{*}{ Amebapores } & Pore forming proteins & Leippe et al., 1991 \\
\hline & All three types induce pore formation in synthetic liposomes & Andrä et al., 2003 \\
\hline Amebapore A & Active at low pH 5.2. May play a role in host cell killing before ingestion & Andrä et al., 2003 \\
\hline $\begin{array}{l}\text { Amebapore B } \\
\text { Amebapore C }\end{array}$ & $\begin{array}{l}\text { In vitro, purified amebapores showed bactericidal activity against Gram-positive } \\
\text { bacteria at nanomolar concentration } \\
\text { Purified amebapores are cytotoxic to Jurkat or U937 cells at micromolar } \\
\text { concentration }\end{array}$ & Leippe et al., 1994; Andrä et al., 2003 \\
\hline \multirow[t]{3}{*}{ Cysteine proteinases (CPs) } & At least $50 \mathrm{CP}$ genes are encoded and some of them are secretory & Tillack et al., 2007 \\
\hline & $\begin{array}{l}\text { Proteinases act on a variety of host substrates such as mucin, villin, laminin, collagen, } \\
\text { proteoglycan, and extracellular matrix (ECM). It plays a role in pathogenesis by } \\
\text { cleaving MUC mucin and ECM degradation }\end{array}$ & Li et al., 1995; Lidell et al., 2006 \\
\hline & $\begin{array}{l}\text { In vivo, overexpression of EhCP5 (EhCP5) increases liver abscess formation } \\
\text { compared to wild-type controls. Other CPs like EhCP1 or EhCP2 overexpression had } \\
\text { no effect }\end{array}$ & $\begin{array}{l}\text { Hellberg et al., 2001; Tillack et al., } \\
2006\end{array}$ \\
\hline \multirow[t]{2}{*}{$\begin{array}{l}\text { Membrane proteins: Gal/GalNAc } \\
\text { lectin associated }\end{array}$} & $\begin{array}{l}\text { 35kDa light subunit of the Gal/GalNAc lectin and surface-localized thiol-dependent } \\
\text { peroxidase }\end{array}$ & Ankri et al., 1999; Sen et al., 2007 \\
\hline & Antisense inhibition of both of these prevents cell killing and deceased liver abscess & Ankri et al., 1999; Sen et al., 2007 \\
\hline $\begin{array}{l}\text { EhSTIRPs (Eh serine, threonine and } \\
\text { isoleucine rice proteins) }\end{array}$ & Silenced by dsRNA resulted in defects in both adhesion and cytotoxicity & MacFarlane and Singh, 2007 \\
\hline $\begin{array}{l}\text { EhTMKB1-9 (Eh transmembrane } \\
\text { kinase B1-9) }\end{array}$ & $\begin{array}{l}\text { Antisense inhibition of this protein showed defects in both adhesion and host cell } \\
\text { killing }\end{array}$ & Shrimal et al., 2010 \\
\hline \multirow{2}{*}{$\begin{array}{l}\text { KERP1 (Lysine and glutamic acid rice } \\
\text { protein 1) }\end{array}$} & Parasite membrane protein binds to host cell membrane & Santi-Rocca et al., 2008 \\
\hline & $\begin{array}{l}\text { Antisense inhibition of this protein failed to decrease mRNA but due to affinity for host } \\
\text { cell membranes, it might have role in cytotoxicity }\end{array}$ & \\
\hline
\end{tabular}

Eh killing of hepatocyte and immune cell was not dependent or mediated by the classical Fas/Fas ligand or TNF $\alpha$ receptor pathway (Seydel and Stanley, 1998). Mice lacking Fas or producing a mutated non-functional Fas protein developed amebic ALA similar to wild type mice. Similarly, TNF receptor knockout mice and wild type mice develop comparable ALA (Seydel and Stanley, 1998). Eh induces a non-classical pathway of apoptosis that may have an important role in pathogenesis (Seydel and Stanley, 1998; Huston et al., 2000). Apoptotic cell death is immunologically silent, thus induction of host cell apoptosis by $E h$ tricks the host cell to kill itself without evoking an inflammatory response to avoid being detected by other immune cells. The importance of apoptosis in regards to amebic virulence is brought to light by studies of the leptin-signaling pathway. The hormone leptin is linked to malnutrition (signals satiety) and regulates the immune response to infection through the Th1 inflammatory response and by preventing apoptosis (Wilson et al., 2012). Leptin signaling provides protection from mucosal destruction and experiments in mice showed the anti-apoptotic role of leptin in gut epithelia (Guo et al., 2011). Polymorphism (even a single amino acid substitution) in the leptin receptor was found to be associated with increased $E h$ infection susceptibility (Duggal et al., 2011).

\section{Phagocytosis by E. histolytica}

The fate of Eh induced apoptotic host cells (Huston et al., 2003) and subsequent phagocytosis may play an important role in the host-parasite relationship in amebiasis. Amebae induced phagocytosis of erythrocyte is one of the possible distinctive feature of $E h$ from the commensal E. dispar (González-Ruiz et al., 1994). In multicellular organisms, phagocytosis is the last step of the apoptotic pathway to clear dead cells without provoking an inflammatory response by the toxic components of dead cells (Figure 1D; Savill and Fadok, 2000; Fadok et al., 2001). Similarly, apoptotic host cells are phagocytosed by Eh with the help of exposed phosphatidylserine (Huston et al., 2003). As Eh rapidly clears apoptotically killed host cells by phagocytosis, this limits the spillage of toxic intracellular contents from killed cells. Through this strategy Eh restrains host inflammatory responses and build up prolonged infection.

Eh-induced phagocytosis is important for pathogenicity but very little is known about the amebic receptors and the corresponding ligands that they bind to. Adherence with host cells by parasite Gal-lectin is critical for cell death but blocking of adherence does not prevent phagocytosis (Teixeira et al., 2008). This suggests the sequential exposure of new ligands on dying cells as well as the recruitment of new receptors on Eh in addition to the Gal-lectin following host cell killing (Teixeira et al., 2008). From an evolutionary concept, Eh phagocytoses bacteria for nutrient acquisition; therefore amebae preferentially recognize and phagocytose apoptotic cells that have surface similarities with bacteria (Teixeira et al., 2008).

\section{Ameba Trogocytosis}

Recently, a new mechanism of Eh killing came to light. Using live cell imaging technology it was discovered that following host 


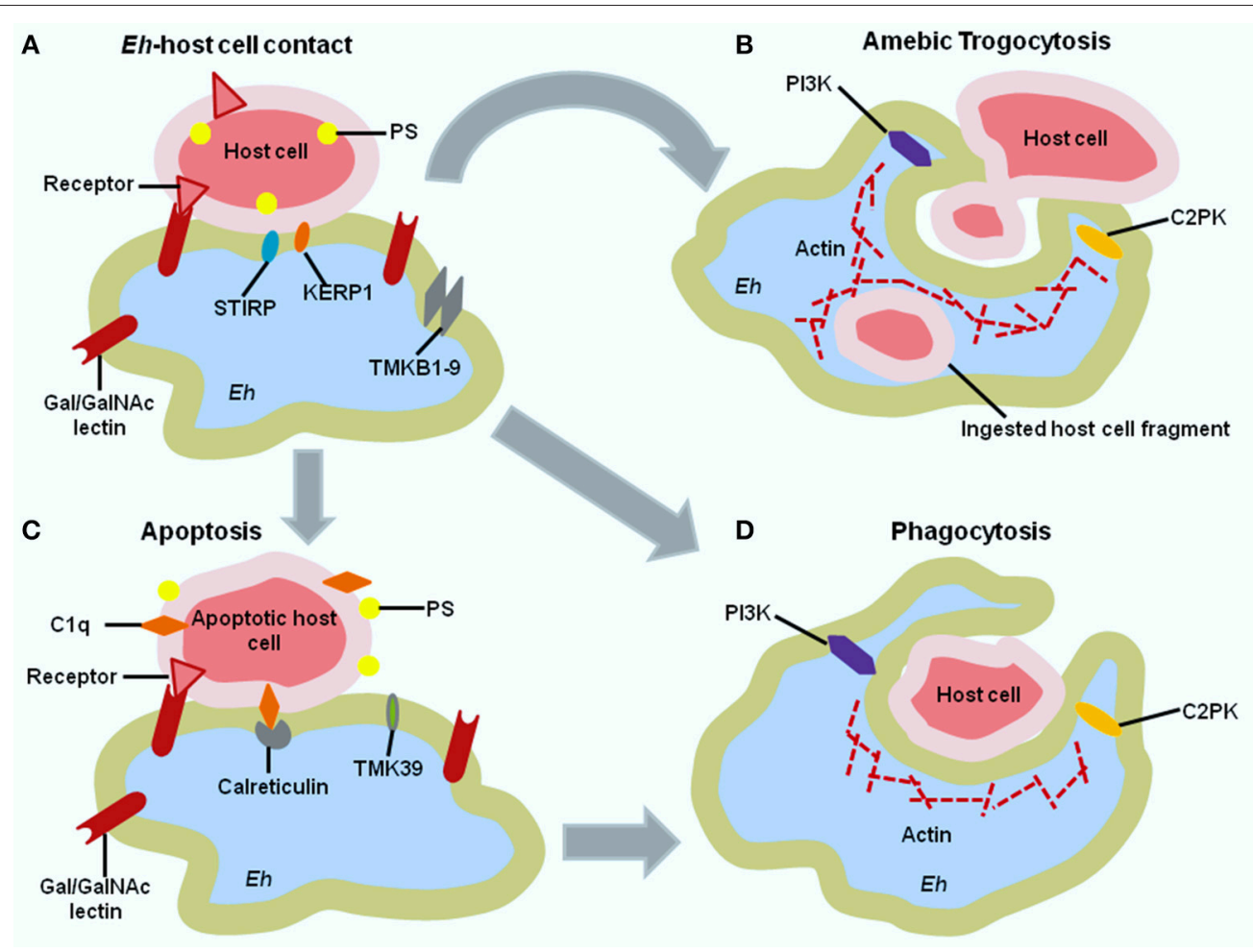

FIGURE 1 | Immune evasion of $\boldsymbol{E}$. histolytica (Eh) by host cell killing. (A) Contact between Eh and host cell is mediated by the Gal-lectin and host cell surface Gal and GalNAc receptors. Other amebic proteins involved in host cell attachment include the trans-membrane serine, threonine, and isoleucine proteins (STIRP) and transmembrane kinase family member TMKb1-9. After Eh-host contact, three events can take place-(B) amebic trogocytosis (C) apoptotic cell death (D) phagocytosis. In (B) larger cells undergo amebic trogocytosis. Amebic trogocytosis require PI3K and C2PK signal transduction for actin polymerization. (C) Host cells that have been induced to undergo apoptosis express phosphatidylserine (PS) and C1q complement protein that induce opsonization by ameba involving amebic calreticulin receptor. Finally, in (D) both apoptotically death cell and smaller cell undergo phagocytosis. Signal transduction for phagocytosis is also mediated by PI3K and EhC2PK and influences actin polymerization. PI3K-phosphoinositide 3 kinase, C2PK-C2 domain containing protein kinase, TMK39-Transmembrane kinase family member.

cell attachment, Eh trophozoites ingest separate parts (bites) of host cells which was termed "amebic trogocytosis" (Figure 1B; Ralston et al., 2014). This was a very rapid process as within $1 \mathrm{~min}$ of attachment amebic trogocytosis is initiated. Due to biting off and ingestion of separate pieces of host cells, intracellular calcium levels were elevated and this triggered ultimate cell death, evidenced by the loss of cell membrane integrity (Ralston et al., 2014). Interestingly, when trophozoites were incubated with either live or pre-killed host cells, only live cells were seen to be trogocytosed by ameba and pre-killed cells were ingested whole (phagocytosed; Ralston et al., 2014; Ralston, 2015). The cell surface characteristics of pre-killed host cells might be different from the directly killed cells and Eh might use this surface difference to determine the type of ingestion (Ralston, 2015). After ingestion of bites, amebae detach from the host cell, and the ingested cell eventually dies. It was speculated that this process contributes to amebic invasion in the colon as Eh can also trogocytose mucosal epithelial cells. Though amebic trogocytosis is a rapid process, this depends on specific conditions like physiological temperature, amoebic actin rearrangements, Gal-lectin, EhC2PK (Eh C2-domain-containing protein kinase), and PI3K (phosphoinositide 3-kinase) signaling
(Ralston et al., 2014). Interference with any of these protein was shown to reduce $E h$ trogocytosis and subsequent decrease in host cell death (Ralston, 2015). It should be noted that trogocytosis also occurs in multicellular organism and different immune cell types but this trogocytosis does not trigger cell death. The exact reason for this distinction is not clear but trogocytosis in multicellular organisms mainly involves the exchange of cell membrane fragments; whereas Eh trogocytosis contains target cell cytoplasm and sometimes organelles (Joly and Hudrisier, 2003; Ralston et al., 2014).

The concept of trogocytosis raises an important question, whether amebic trogocytosis is different from phagocytosis. The signaling proteins involved in amebic trogocytosis also play important roles during Eh phagocytosis but amebic trogocytosis is predominant in living cells (Ralston, 2015). Some factors might take part in the distinction of trogocytosis and phagocytosis like target cell deformability, target cell viability, target cell size etc. (Ralston, 2015). However, the specific signaling pathways that define amebic trogocytosis and phagocytosis in $E h$ are not identified; the relationship or differences between these two processes are not well understood. 


\section{CONCLUSION}

Eh is an enteric dwelling protozoan parasite that causes significant morbidity and mortality in developing countries. This parasite can develop a harmless colonization in the colon and for unknown reasons it can become a pathogenic phenotype. With the pathogenic phenotype, Eh disrupts innate mucosal barriers and penetrates the underlying lamina propria where the parasite develops potent cytotoxic activity and extensive tissue destruction. It is still not clear how or what factors induce this pathogenic phenotype. Human and parasite genetics along with environmental factors might have a role as it has been found that not all children are equally susceptible to infection. Malnutrition extensively increases disease susceptibility. Gut microbiome also influence Eh infection susceptibility. Both host innate and adaptive immune response take part in the elimination of invasive Eh. The host immune system builds up a rapid inflammatory response by the secretion of cytokines/chemokines, recruitment of immune cells (neutrophils, macrophages), and the activation of inflammasome to control invasive parasites. This parasite also

\section{REFERENCES}

Andrä, J., Herbst, R., and Leippe, M. (2003). Amoebapores, archaic effector peptides of protozoan origin, are discharged into phagosomes and kill bacteria by permeabilizing their membranes. Dev. Comp. Immunol. 27, 291-304. doi: 10.1016/S0145-305X(02)00106-4

Ankri, S., Padilla-Vaca, F., Stolarsky, T., Koole, L., Katz, U., and Mirelman, D. (1999). Antisense inhibition of expression of the light subunit $(35 \mathrm{kDa})$ of the Gal/GalNac lectin complex inhibits Entamoeba histolytica virulence. Mol. Microbiol. 33, 327-337. doi: 10.1046/j.1365-2958.1999.01476.x

Becker, S. M., Cho, K.-N., Guo, X., Fendig, K., Oosman, M. N., Whitehead, R., et al. (2010). Epithelial cell apoptosis facilitates Entamoeba histolytica infection in the gut. Am. J. Pathol. 176, 1316-1322. doi: 10.2353/ajpath.2010.090740

Braga, L. L., Ninomiya, H., McCoy, J. J., Eacker, S., Wiedmer, T., Pham, C., et al. (1992). Inhibition of the complement membrane attack complex by the galactose-specific adhesion of Entamoeba histolytica. J. Clin. Invest. 90, 1131. doi: 10.1172/JCI115931

Bruchhaus, I., Richter, S., and Tannich, E. (1998). Recombinant expression and biochemical characterization of an NADPH: flavin oxidoreductase from Entamoeba histolytica. Biochem. J. 330, 1217-1221. doi: 10.1042/bj3301217

Campos-Rodríguezp, R., and Jarillo-Luna, A. (2005). The pathogenicity of Entamoeba histolytica is related to the capacity of evading innate immunity. Parasite Immunol. 27, 1-8. doi: 10.1111/j.1365-3024.2005.00743.x

Chadee, K., Petri, W. A. Jr., Innes, D. J., and Ravdin, J. I. (1987). Rat and human colonic mucins bind to and inhibit adherence lectin of Entamoeba histolytica. J. Clin. Invest. 80, 1245. doi: 10.1172/JCI113199

Cobo, E. R., He, C., Hirata, K., Hwang, G., Tran, U., Eckmann, L., et al. (2012). Entamoeba histolytica induces intestinal cathelicidins but is resistant to cathelicidin-mediated killing. Infect. Immun. 80, 143-149. doi: 10.1128/IAI.05029-11

Davis, P. H., Zhang, X., Guo, J., Townsend, R. R., and Stanley, S. L. (2006). Comparative proteomic analysis of two Entamoeba histolytica strains with different virulence phenotypes identifies peroxiredoxin as an important component of amoebic virulence. Mol. Microbiol. 61, 1523-1532. doi: 10.1111/j.1365-2958.2006.05344.x

Denis, M., and Chadee, K. (1989). Human neutrophils activated by interferongamma and tumour necrosis factor-alpha kill Entamoeba histolytica trophozoites in vitro. J. Leukocyte Biol. 46, 270-274.

Dey, I., Keller, K., Belley, A., and Chadee, K. (2003). Identification and characterization of a cyclooxygenase-like enzyme from Entamoeba histolytica. develops multiple strategies to subvert host immune responses and to promote its own survival. Eh induces host cell killing primarily by apoptosis, which is a non-inflammatory cell death mechanism. Induction of apoptotic cell death is an active and stepwise process. After inducing cell death, the parasite also clears the corpse by phagocytosis to inhibit further inflammatory responses. Another mechanism is amebic trogocytosis where Eh bites live cells very rapidly and induces cell death. The proper characterization of proteins, receptor/ligand interaction involved in parasite adherence, cell killing, phagocytosis, and amebic trogocytosis will provide promise of future vaccine candidates.

\section{AUTHOR CONTRIBUTIONS}

$\mathrm{SB}$, JQ, and KC wrote and edit the manuscript.

\section{FUNDING}

This work was supported by a grant from the Natural Sciences and Engineering Research Council of Canada (NSERC). SB and JQ is supported by scholarships from NSERC CREATE.

Proc. Natl. Acad. Sci. U.S.A. 100, 13561-13566. doi: 10.1073/pnas.18358 63100

Duggal, P., Guo, X., Haque, R., Peterson, K. M., Ricklefs, S., Mondal, D., et al. (2011). A mutation in the leptin receptor is associated with Entamoeba histolytica infection in children. J. Clin. Invest. 121, 1191. doi: 10.1172/JCI45294

Elnekave, K., Siman-Tov, R., and Ankri, S. (2003). Consumption of L-arginine mediated by Entamoeba histolytica L-arginase (EhArg) inhibits amoebicidal activity and nitric oxide production by activated macrophages. Parasite Immunol. 25, 597-608. doi: 10.1111/j.0141-9838.2004. 00669.x

Fadok, V. A., Bratton, D. L., and Henson, P. M. (2001). Phagocyte receptors for apoptotic cells: recognition, uptake, and consequences. J. Clin. Invest. 108, 957. doi: 10.1172/JCI200114122

Ghadirian, E., and Denis, M. (1992). Entamoeba histolytica extract and interferon-gamma activation of macrophage-mediated amoebicidal function. Immunobiology 185, 1-10. doi: 10.1016/S0171-2985(11)80312-8

González-Ruiz, A., Haque, R., Aguirre, A., Castañón, G., Hall, A., Guhl, F., et al. (1994). Value of microscopy in the diagnosis of dysentery associated with invasive Entamoeba histolytica. J. Clin. Pathol. 47, 236-239. doi: 10.1136/jcp.47.3.236

Guerrant, R. L., Brush, J., Ravdin, J. I., Sullivan, J. A., and Mandell, G. L. (1981). Interaction between Entamoeba histolytica and human polymorphonuclear neutrophils. J. Infect. Dis. 143, 83-93. doi: 10.1093/infdis/143.1.83

Guo, X., Houpt, E., and Petri, W. A. (2007). Crosstalk at the initial encounter: interplay between host defense and ameba survival strategies. Curr. Opin. Immunol. 19, 376-384. doi: 10.1016/j.coi.2007.07.005

Guo, X., Roberts, M. R., Becker, S. M., Podd, B., Zhang, Y., Chua, S. C., et al. (2011). Leptin signaling in intestinal epithelium mediates resistance to enteric infection by Entamoeba histolytica. Mucosal Immunol. 4, 294-303. doi: $10.1038 / \mathrm{mi} .2010 .76$

Haque, R., Ali, I. M., Sack, R. B., Farr, B. M., Ramakrishnan, G., and Petri, W. A. (2001). Amebiasis and mucosal IgA antibody against the Entamoeba histolytica adherence lectin in Bangladeshi children. J. Infect. Dis. 183, 1787-1793. doi: $10.1086 / 320740$

Haque, R., Mondal, D., Duggal, P., Kabir, M., Roy, S., Farr, B. M., et al. (2006). Entamoeba histolytica infection in children and protection from subsequent amebiasis. Infect. Immun. 74, 904-909. doi: 10.1128/IAI.74.2.904909.2006

Haque, R., Mondal, D., Shu, J., Roy, S., Kabir, M., Davis, A. N., et al. (2007). Correlation of interferon- $\gamma$ production by peripheral blood mononuclear cells 
with childhood malnutrition and susceptibility to amebiasis. Am. J. Trop. Med. Hyg. 76, 340-344.

Hellberg, A., Nickel, R., Lotter, H., Tannich, E., and Bruchhaus, I. (2001). Overexpression of cysteine proteinase 2 in Entamoeba histolytica or Entamoeba dispar increases amoeba-induced monolayer destruction in vitro but does not augment amoebic liver abscess formation in gerbils. Cell. Microbiol. 3, 13-20. doi: 10.1046/j.1462-5822.2001.00086.x

Huston, C. D., Boettner, D. R., Miller-Sims, V., and Petri, W. A. Jr. (2003). Apoptotic killing and phagocytosis of host cells by the parasite Entamoeba histolytica. Infect. Immun. 71, 964-972. doi: 10.1128/IAI.71.2.964-972.2003

Huston, C. D., Houpt, E. R., Mann, B. J., Hahn, C. S., and Petri, W. A. (2000). Caspase 3-dependent killing of host cells by the parasite Entamoeba histolytica. Cell. Microbiol. 2, 617-625. doi: 10.1046/j.1462-5822.2000. 00085.x

Joly, E., and Hudrisier, D. (2003). What is trogocytosis and what is its purpose? Nat. Immunol. 4:815. doi: 10.1038/ni0903-815

Kammanadiminti, S. J., Mann, B. J., Dutil, L., and Chadee, K. (2004). Regulation of Toll-like receptor-2 expression by the Gal-lectin of Entamoeba histolytica. FASEB J. 18, 155-157. doi: 10.1096/fj.03-0578fje

Kaur, U., Sharma, A., Sharma, M., and Vohra, H. (2004). Distribution of Entamoeba histolytica Gal/GalNAc lectin-specific antibody response in an endemic area. Scand. J. Immunol. 60, 524-528. doi: 10.1111/j.03009475.2004.01512.x

Korpe, P. S., Liu, Y., Siddique, A., Kabir, M., Ralston, K., Ma, J. Z., et al. (2013). Breast milk parasite-specific antibodies and protection from amebiasis and cryptosporidiosis in Bangladeshi infants: a prospective cohort study. Clin. Infect. Dis. 56, 988-992. doi: 10.1093/cid/cis1044

Leippe, M., Andra, J., and Müller-Eberhard, H. J. (1994). Cytolytic and antibacterial activity of synthetic peptides derived from amoebapore, the poreforming peptide of Entamoeba histolytica. Proc. Natl. Acad. Sci. U.S.A. 91, 2602-2606. doi: 10.1073/pnas.91.7.2602

Leippe, M., Ebel, S., Schoenberger, O. L., Horstmann, R. D., and Müller-Eberhard, H. J. (1991). Pore-forming peptide of pathogenic Entamoeba histolytica. Proc. Natl. Acad. Sci. U.S.A. 88, 7659-7663. doi: 10.1073/pnas.88.17.7659

Li, E., Yang, W. G., Zhang, T., and Stanley, S. L. (1995). Interaction of laminin with Entamoeba histolytica cysteine proteinases and its effect on amebic pathogenesis. Infect. Immun. 63, 4150-4153. doi: 10.1016/0169-4758(95) 80056-5

Lidell, M. E., Moncada, D. M., Chadee, K., and Hansson, G. C. (2006). Entamoeba histolytica cysteine proteases cleave the MUC2 mucin in its C-terminal domain and dissolve the protective colonic mucus gel. Proc. Natl. Acad. Sci. U.S.A. 103, 9298-9303. doi: 10.1073/pnas.0600623103

Lin, J. Y., Keller, K., and Chadee, K. (1993). Entamoeba histolytica proteins modulate the respiratory burst potential by murine macrophages. Immunology $78,291$.

Lin, J.-Y., Seguin, R., Keller, K., and Chadee, K. (1994). Tumor necrosis factor alpha augments nitric oxide-dependent macrophage cytotoxicity against Entamoeba histolytica by enhanced expression of the nitric oxide synthase gene. Infect. Immun. 62, 1534-1541.

MacFarlane, R. C., and Singh, U. (2007). Identification of an Entamoeba histolytica serine-, threonine-, and isoleucine-rich protein with roles in adhesion and cytotoxicity. Eukaryotic Cell 6, 2139-2146. doi: 10.1128/EC.00174-07

Mondal, D., Petri, W. A., Sack, R. B., Kirkpatrick, B. D., and Haque, R. (2006). Entamoeba histolytica-associated diarrheal illness is negatively associated with the growth of preschool children: evidence from a prospective study. Trans. $R$. Soc. Trop. Med. Hyg. 100, 1032-1038. doi: 10.1016/j.trstmh.2005.12.012

Moonah, S. N., Jiang, N. M., and Petri, W. A. Jr. (2013). Host immune response to intestinal amebiasis. PLoS Pathog. 9:e1003489. doi: 10.1371/journal.ppat.1003489

Mortimer, L., and Chadee, K. (2010). The immunopathogenesis of Entamoeba histolytica. Exp. Parasitol. 126, 366-380. doi: 10.1016/j.exppara.2010.03.005

Mortimer, L., Moreau, F., Cornick, S., and Chadee, K. (2014). Gal-lectin-dependent contact activates the inflammasome by invasive Entamoeba histolytica. Mucosal Immunol. 7, 829-841. doi: 10.1038/mi.2013.100

Mortimer, L., Moreau, F., Cornick, S., and Chadee, K. (2015). The NLRP3 inflammasome is a pathogen sensor for invasive Entamoeba histolytica via activation of $\alpha 5 \beta 1$ integrin at the macrophage-amebae intercellular junction. PLoS Pathog. 11:e1004887. doi: 10.1371/journal.ppat.1004887
Petri, W. A. (2003). Therapy of intestinal protozoa. Trends Parasitol. 19, 523-526. doi: 10.1016/j.pt.2003.09.003

Que, X., and Reed, S. L. (1997). The role of extracellular cysteine proteinases in pathogenesis of Entamoeba histolytica invasion. Parasitol. Today 13, 190-194. doi: 10.1016/S0169-4758(97)01043-0

Ralston, K. S. (2015). Chew on this: amoebic trogocytosis and host cell killing by Entamoeba histolytica. Trends Parasitol. 31, 442-452. doi: 10.1016/j.pt.2015.05.003

Ralston, K. S., and Petri, W. A. (2011a). Tissue destruction and invasion by Entamoeba histolytica. Trends Parasitol. 27, 254-263. doi: 10.1016/j.pt.2011.02.006

Ralston, K. S., and Petri, W. A. (2011b). The ways of a killer: how does Entamoeba histolytica elicit host cell death? Essays Biochem. 51, 193-210. doi: 10.1042/bse0510193

Ralston, K. S., Solga, M. D., Mackey-Lawrence, N. M., Bhattacharya, A., and Petri, W. A. Jr. (2014). Trogocytosis by Entamoeba histolytica contributes to cell killing and tissue invasion. Nature 508, 526-530. doi: 10.1038/nature13242

Ravdin, J. I., and Guerrant, R. L. (1981). Role of adherence in cytopathogenic mechanisms of Entamoeba histolytica: study with mammalian tissue culture cells and human erythrocytes. J. Clin. Invest. 68, 1305. doi: 10.1172/JCI110377

Ravdin, J. I., Sperelakis, N., and Guerrant, R. L. (1982). Effect of ion channel inhibitors on the cytopathogenicity of Entamoeba histolytica. J. Infect. Dis. 146, 335-340. doi: 10.1093/infdis/146.3.335

Reed, S. L., Ember, J. A., Herdman, D. S., DiScipio, R. G., Hugli, T. E., and Gigli, I. (1995). The extracellular neutral cysteine proteinase of Entamoeba histolytica degrades anaphylatoxins C3a and C5a. J. Immunol. 155, 266-274.

Rico, G., Leandro, E., Rojas, S., Gimenéz, J. A., and Kretschmer, R. R. (2003). The monocyte locomotion inhibitory factor produced by Entamoeba histolytica inhibits induced nitric oxide production in human leukocytes. Parasitol. Res. 90, 264-267. doi: 10.1007/s00436-002-0780-7

Saffer, L. D., and Petri, W. A. (1991). Role of the galactose lectin of Entamoeba histolytica in adherence-dependent killing of mammalian cells. Infect. Immun. 59, 4681-4683.

Santi-Rocca, J., Weber, C., Guigon, G., Sismeiro, O., Coppee, J. Y., and Guillen, N. (2008). The lysine and glutamic acid-rich protein KERP1 plays a role in Entamoeba histolytica liver abscess pathogenesis. Cell. Microbiol. 10, 202-217. doi: 10.1111/j.1462-5822.2007.01030.x

Savill, J., and Fadok, V. (2000). Corpse clearance defines the meaning of cell death. Nature 407, 784-788. doi: 10.1038/35037722

Sen, A., Chatterjee, N. S., Akbar, M. A., Nandi, N., and Das, P. (2007). The 29-kilodalton thiol-dependent peroxidase of Entamoeba histolytica is a factor involved in pathogenesis and survival of the parasite during oxidative stress. Eukaryotic Cell 6, 664-673. doi: 10.1128/EC.00308-06

Seydel, K. B., Smith, S. J., and Stanley, S. L. (2000). Innate immunity to amebic liver abscess is dependent on gamma interferon and nitric oxide in a murine model of disease. Infect. Immun. 68, 400-402. doi: 10.1128/IAI.68.1.400-402.2000

Seydel, K. B., and Stanley, S. L. (1998). Entamoeba histolytica induces host cell death in amebic liver abscess by a non-Fas-dependent, non-tumor necrosis factor alpha-dependent pathway of apoptosis. Infect. Immun. 66, 2980-2983.

Shrimal, S., Bhattacharya, S., and Bhattacharya, A. (2010). Serum-dependent selective expression of EhTMKB1-9, a member of Entamoeba histolytica B1 family of transmembrane kinases. PLoS Pathog. 6:e1000929. doi: 10.1371/journal.ppat.1000929

Sim, S., Yong, T.-S., Park, S.-J., Im, K.-I., Kong, Y., Ryu, J.-S., et al. (2005). NADPH oxidase-derived reactive oxygen species-mediated activation of ERK1/2 is required for apoptosis of human neutrophils induced by Entamoeba histolytica. J. Immunol. 174, 4279-4288. doi: 10.4049/jimmunol.174.7.4279

Stanley, S. L. (2003). Amoebiasis. Lancet 361, 1025-1034. doi: 10.1016/S01406736(03)12830-9

Teixeira, J. E., Heron, B. T., and Huston, C. D. (2008). C1q-and collectindependent phagocytosis of apoptotic host cells by the intestinal protozoan Entamoeba histolytica. J. Infect. Dis. 198, 1062-1070. doi: 10.1086/591628

Tillack, M., Biller, L., Irmer, H., Freitas, M., Gomes, M. A., Tannich, E., et al. (2007). The Entamoeba histolytica genome: primary structure and expression of proteolytic enzymes. BMC Genomics 8:170. doi: 10.1186/1471-2164-8-170

Tillack, M., Nowak, N., Lotter, H., Bracha, R., Mirelman, D., Tannich, E., et al. (2006). Increased expression of the major cysteine proteinases by stable episomal transfection underlines the important role of EhCP5 for the 
pathogenicity of Entamoeba histolytica. Mol. Biochem. Parasitol. 149, 58-64. doi: 10.1016/j.molbiopara.2006.04.009

Voigt, H., Olivo, J.-C., Sansonetti, P., and Guillén, N. (1999). Myosin IB from Entamoeba histolytica is involved in phagocytosis of human erythrocytes. J. Cell Sci. 112, 1191-1201.

Wang, W., and Chadee, K. (1995). Entamoeba histolytica suppresses gamma interferon-induced macrophage class II major histocompatibility complex Ia molecule and IA beta mRNA expression by a prostaglandin E2-dependent mechanism. Infect. Immun. 63, 1089-1094.

Wang, W., Keller, K., and Chadee, K. (1994). Entamoeba histolytica modulates the nitric oxide synthase gene and nitric oxide production by macrophages for cytotoxicity against amoebae and tumour cells. Immunology 83,601 .

Wilson, I. W., Weedall, G. D., and Hall, N. (2012). Host-parasite interactions in Entamoeba histolytica and Entamoeba dispar: what have we learned from their genomes? Parasite Immunol. 34, 90-99. doi: 10.1111/j.1365-3024.2011. 01325.x
Yu, Y., and Chadee, K. (1997). Entamoeba histolytica stimulates interleukin 8 from human colonic epithelial cells without parasite-enterocyte contact. Gastroenterology 112, 1536-1547. doi: 10.1016/S0016-5085(97)70035-0

Zambrano-Villa, S., Rosales-Borjas, D., Carrero, J. C., and Ortiz-Ortiz, L. (2002). How protozoan parasites evade the immune response. Trends Parasitol. 18, 272-278. doi: 10.1016/S1471-4922(02)02289-4

Conflict of Interest Statement: The authors declare that the research was conducted in the absence of any commercial or financial relationships that could be construed as a potential conflict of interest.

Copyright (c) 2015 Begum, Quach and Chadee. This is an open-access article distributed under the terms of the Creative Commons Attribution License (CC BY). The use, distribution or reproduction in other forums is permitted, provided the original author(s) or licensor are credited and that the original publication in this journal is cited, in accordance with accepted academic practice. No use, distribution or reproduction is permitted which does not comply with these terms. 